\title{
Selection of reference genes for quantitative real-time PCR in a rat asphyxial cardiac arrest model Kristina Langnaese*1, Robin John ${ }^{1}$, Hannes Schweizer ${ }^{1}$, Uwe Ebmeyer ${ }^{2}$ and Gerburg Keilhoff 1
}

\author{
Address: ${ }^{1}$ Institute of Medical Neurobiology, University of Magdeburg, Leipziger Str. 44, D-39120 Magdeburg, Germany and 2Department of \\ Anaesthesiology and Critical Care Medicine, University of Magdeburg, Leipziger Str. 44, D-39120 Magdeburg, Germany \\ Email: Kristina Langnaese* - kristina.langnaese@med.ovgu.de; Robin John - robinjohn@t-online.de; \\ Hannes Schweizer - hannes_schweizer@web.de; Uwe Ebmeyer - uwe.ebmeyer@med.ovgu.de; Gerburg Keilhoff - gerburg.keilhoff@med.ovgu.de \\ * Corresponding author
}

Published: 28 May 2008

BMC Molecular Biology 2008, 9:53 doi:10.1186/147/-2199-9-53

This article is available from: http://www.biomedcentral.com/147I-2199/9/53

(c) 2008 Langnaese et al; licensee BioMed Central Ltd.

This is an Open Access article distributed under the terms of the Creative Commons Attribution License (http://creativecommons.org/licenses/by/2.0), which permits unrestricted use, distribution, and reproduction in any medium, provided the original work is properly cited.
Received: 14 February 2008

Accepted: 28 May 2008

\begin{abstract}
Background: Cardiac arrest, and the associated arrest of blood circulation, immediately leads to permanent brain damage because of the exhaustion of oxygen, glucose and energy resources in the brain. Most hippocampal CAI neurons die during the first week post the insult. Molecular data concerning the recovery after resuscitation are sparse and limited to the early time period. Expression analysis of marker genes via quantitative real-time RT-PCR enables to follow up the remodeling process. However, proper validation of the applied normalization strategy is a crucial prerequisite for reliable conclusions.

Therefore, the present study aimed to determine the expression stability of ten commonly used reference genes (Actb, actin, beta; B2m, beta-2 microglobulin;CypA, cyclophilin A; Gapdh, glyceraldehyde-3-phosphate dehydrogenase; Hprt, hypoxanthine guanine phosphoribosyl transferase; Pgkl, phosphoglycerate kinase I; Rpl/3a, ribosomal protein LI3A; Sdha, succinat dehydrogenase complex, subunit a, flavoprotein (Fp); Tbp, TATA box binding protein; Ywhaz, tyrosine 3-monooxygenase/tryptophan 5-monooxygenase activation protein, zeta polypeptide) in the rat hippocampus four, seven and twenty-one days after cardiac arrest. Moreover, experimental groups treated with the anti-inflammatory and anti-apoptotic drug minocycline have been included in the study as well.
\end{abstract}

Results: The microglial marker Mac-I, used as a target gene to validate the experimental model, was found to be upregulated about 10- to 20 -fold after cardiac arrest.

Expression stability of candidate reference genes was analyzed using geNorm and NormFinder software tools. Several of these genes behave rather stable. CypA and Pgkl were identified by geNorm as the two most stable genes 4 and 21 days after asphyxial cardiac arrest, CypA and Gapdh at 7 days post treatment. $B 2 m$ turned out to be the most variable candidate reference gene, being about 2-fold upregulated in the cardiac arrest treatment groups.

Conclusion: We have validated endogenous control genes for QRT-PCR analysis of gene expression in rat hippocampus after resuscitation from cardiac arrest. For normalization purposes in gene profiling studies a combination of CypA and Pgkl should be considered 4 and 21 days post injury, whereas CypA and Gapdh is the best combination at 7 days. CypA is most favorable if restriction to a single reference gene for all time points is required. 


\section{Background}

Patho-physiological and biochemical processes during a cardiac arrest, resuscitation, and after restoration of spontaneous circulation are extremely complex, and thus far, poorly understood. Under normothermic conditions brain damage begins to develop after 4-5 min of no-flow $[1,2]$ due to total circulatory arrest, mainly because of the exhaustion of oxygen, glucose and energy resources in brain and other parts of the organism. Eight minutes of asphyxiation - resulting in approximately five minutes of complete none perfusion - causes major to subtotal neuronal damage within the CA1 region of hippocampus, as revealed by haematoxylin-eosin staining [3]. Already eight hours after the insult damaged neurons are characterized by shrunken cell bodies and pyknotic nuclei. Necrotic neurons are partially resorbed within the first week after the insult.

This histologically visible massive remodeling process can be expected to be accompanied with considerable changes in mRNA and protein expression. Only few data are available and these are limited to the early period after the insult. For example the level of the stress related proteins HSP70 and HSP40 is increased $12 \mathrm{~h}$ after the ischemic insult [4], as well as the mRNA amount of HSP10, a heat shock protein of the mitochondrial matrix [5]. Caspase-1 and -3 are detectable immunohistochemically $72 \mathrm{~h}$ after asphyxia [6]. Moreover, the mRNAs of MMP-9, a matrix metalloproteinase, and TIMP-1, tissue inhibitor 1 of matrix metalloproteinase, are upregulated $6 \mathrm{~h}$ after the insult [7]. At $24 \mathrm{~h}$ after cardiac arrest BDNF transcripts, namely those containing exons 1 and 3, as well as BDNF protein are increased $[8,9]$.

When attempting to analyze the molecular biological consequences of an ischemic insult due to asphyxial cardiac arrest (ACA), a model of neurological injury after sudden cardiac arrest, real-time quantitative RT-PCR (qRT-PCR) is the method of choice for monitoring alterations of gene expression patterns that accompany the recovery process in the damaged brain. qRT-PCR enables a sensitive and accurate quantification of mRNA expression levels.

However, selection of an appropriate normalization strategy is of crucial importance for data interpretation, because data need to be controlled for the experimental error introduced during the multistage process of isolating and processing RNA [10-12].

The most frequently applied approach for normalization is the use of an internal control or reference gene, often referred to as housekeeping gene. A growing number of recently published articles reflect the need to carefully validate reference genes for each particular experimental model [13-16]. To be used as a suitable reference gene sev- eral criteria should be fulfilled. The expression should be stable, not regulated or influenced by the experimental conditions or treatments. In addition, the expression level of the reference gene should be similar to the target genes in the analyzed samples. The amplification of the reference gene should be RNA-specific. The importance of choosing a reliable reference gene is underlined by the fact, that the use of an unstable reference gene for normalization will obscure real changes or produce artificial changes in gene expression $[13,17]$. Therefore, the validation of reference genes for each experimental situation is a crucial requirement for the acquisition of biological meaningful data $[10,18,19]$.

The aim of this study was to identify the most stable reference gene, or a combination of the most stable genes, in rat hippocampus during the long term recovery after global hypoxic ischemia. We therefore evaluated ten commonly used housekeeping genes for their change in the ACA experimental model at 4,7 and 21 days after the insult. The analysis was conducted in parallel also with experimental groups that received treatment with minocycline. Minocycline is a semisynthetic second-generation tetracycline with broad-spectrum antimicrobial activity, which has been used for decades in humans to treat infectious diseases [20]. In addition to its antimicrobial actions minocycline was shown to exert beneficial effects in a variety of models of neurological disorders (reviewed in [2124]). This application area relies on minocycline's antiinflammatory and anti-apoptotic properties. For example minocycline has been demonstrated to reduce infarct size after focal cerebral ischemia [25-28], to inhibit ischemia induced activation of microglia and to prevent upregulation of ischemia-induced mRNAs $[25,29]$. Therefore, the analysis of minocycline's effectiveness is desirable in the ACA experimental model too. However, since such a pharmacological treatment might up- or downregulate not only target genes, but also housekeeping genes, the respective experimental groups were already included in this study.

Our results will provide information about appropriate reference genes for the normalization of qPCR data during long time recovery studies in the cardiac arrest model necessary for future gene expression studies.

\section{Results}

Ten candidate reference genes were selected from commonly used control genes. Genes with different functions were chosen to avoid genes belonging to the same biological pathways that might be coregulated (see Tab. 1 and 2 for gene names and function).

Using real-time PCR we evaluated the expression of these candidate reference genes in rat hippocampus under four 
Table I: Primer sequences and amplicon characteristics

\begin{tabular}{|c|c|c|c|c|c|c|c|}
\hline Gene & Sequence & Reference $^{\text {a }}$ & $\begin{array}{l}\text { Position } \\
\text { cDNA b }\end{array}$ & $\begin{array}{l}\text { Position } \\
\text { gene }\end{array}$ & $\begin{array}{l}\text { Amplicon } \\
\text { length (bp) }\end{array}$ & $\begin{array}{l}\text { Product } \\
\text { TMe, }\left({ }^{\circ} \mathrm{C}\right)\end{array}$ & $\begin{array}{l}\text { PCR } \\
\text { efficiency (\%) }\end{array}$ \\
\hline \multirow[t]{2}{*}{ Gapdh } & 5'-CAACTCCCTCAAGATTGTCAGCAA-3' & NM_0I7008 & $493-516$ & Int. span. & 118 & 82.9 & 105 \\
\hline & 5-'GGCATGGACTGTGGTCATGA-3' & NC_005I03 & $6|0-59|$ & & & & \\
\hline \multirow[t]{2}{*}{$A c t b^{c}$} & 5'-AAGTCCСТCACССТCCCAAAAG-3' & V01217 & 3474-3495 & Exon & 97 & 82.9 & 92.5 \\
\hline & 5'-AAGCAATGCTGTCACCTTCCC-3' & V01217 & $3570-3550$ & & & & \\
\hline \multirow[t]{2}{*}{ СурА с } & 5'-TATCTGCACTGCCAAGACTGAGTG-3' & MI9533 & $381-404$ & Int. span. & 126 & 82.0 & 98 \\
\hline & 5'-CTTCTTGCTGGTCTTGCCATTCC-3' & NW_047430 & $507-485$ & & & & \\
\hline \multirow[t]{2}{*}{$B 2 m$} & 5'-CGAGACCGATGTATATGCTTGC-3' & NM_0I25I2 & $286-307$ & Int. span. & 114 & 79.8 & 92 \\
\hline & 5'-GTCCAGATGATTCAGAGCTCCA-3' & NC_005102 & $399-378$ & & & & \\
\hline \multirow[t]{2}{*}{ Rp//3a } & 5'-GGATCCСTCCACCCTATGACA-3' & NM_I 73340 & $334-354$ & Int. span. & 132 & 83.5 & 100 \\
\hline & 5'-CTGGTACTTCCACCCGACCTC-3' & NC_005100 & $464-444$ & & & & \\
\hline \multirow[t]{2}{*}{ Hprt c } & 5'-CTCATGGACTGATTATGGACAGGAC-3' & NM_0I2583 & 179-203 & Int. span. & 123 & 80.9 & 97 \\
\hline & 5'-GCAGGTCAGCAAAGAACTTATAGCC-3' & NW_048050 & $301-277$ & & & & \\
\hline \multirow[t]{2}{*}{ Ywhaz } & 5'-GATGAAGCCATTGCTGAACTTG-3' & NM_ōI30II & $955-976$ & Int. span. & 117 & 77.6 & 95 \\
\hline & 5'-GTCTCCTTGGGTATCCGATGTC-3' & NC_005106 & $107 \mid-1050$ & & & & \\
\hline \multirow[t]{2}{*}{ Sdha } & 5'-TCCTTCCСACTGTGCATTACAA-3' & NM_I30428 & $1222-1243$ & Int. span. & 105 & 81.4 & 98 \\
\hline & 5'-CGTACAGACCAGGCACAATCTG-3' & NC_005I00 & $1326-1305$ & & & & \\
\hline \multirow[t]{2}{*}{$P g k l$} & 5'-ATGCAAAGACTGGCCAAGCTAC-3' & NM_05329I & $969-990$ & Int. span. & 104 & 81.9 & 99 \\
\hline & 5'-AGCCACAGCCTCAGCATATTTC-3' & NC_005I 20 & $|072-105|$ & & & & \\
\hline \multirow[t]{2}{*}{$T b p$} & 5'-TGGGATTGTACCACAGCTCCA-3' & NM_001004I98 & $679-699$ & Int. span. & $|3|$ & 78.2 & 100 \\
\hline & 5'-CTCATGATGACTGCAGCAAACC-3' & NC_005100 & $810-789$ & & & & \\
\hline \multirow[t]{2}{*}{$M a c-I^{d}$} & 5'-CTGCCTCAGGGATCCGTAAAG-3' & NM_0I27II & $680-700$ & Int. span. & 150 & 79.8 & 101 \\
\hline & 5'-CCTCTGCCTCAGGAATGACATC-3' & NW_outo4562 & $829-808$ & & & & \\
\hline
\end{tabular}

a Genebank accession number of cDNA (upper line) and genomic sequences or contigs (lower line), b Position of amplification product within cDNA sequence (genomic sequence for Actb), Exon; both primers bind to the same exon, Int. span.; primers bind on different exons, c Primer sequences according to [46], ${ }^{d}$ Primer sequences according to [47], ${ }^{e}$ melting temperature of specific PCR product, ${ }^{f}$ calculated by MxPro Mx3005P v3.00 software (Stratagene, La Jolla, CA)

different experimental conditions: sham operated animals, sham operated animals with minocycline treatment, ACA and ACA with minocycline treatment. Each of the four experimental groups was analyzed 4 days, 7 days and 21 days after the insult.

\section{Quality assessment of qPCR protocol and qPCR efficiency} Agarose gel electrophoresis of PCR products during the initial optimization experiments revealed single bands for all primer sets (not shown). Moreover, melting curve analysis was performed after each run. This always demonstrated a single homogenous melt peak, confirming specific amplification. The melting temperatures of all PCR products are given in Tab. 1 . Since PCR products of identical size and melting temperature may also arise due to the existence of processed pseudogenes on the genomic DNA [30], which potentially contaminates the samples, additional control experiments were performed. Indeed,

Table 2: Name and function of the genes

\begin{tabular}{|c|c|c|}
\hline Symbol* & Gene name* & Function \\
\hline Gapdh & glyceraldehyde-3-phosphate dehydrogenase & Glycolytic enzyme \\
\hline Actb & actin, beta & Cytoskeletal structural protein \\
\hline CypA (synonym Ppia) & cyclophilin A (peptidyl prolyl isomerase A) & $\begin{array}{l}\text { Catalyzes the cis-trans isomerization of proline imidic } \\
\text { peptide bonds in oligopeptides, accelerating folding }\end{array}$ \\
\hline$B 2 m$ & beta-2 microglobulin & $\begin{array}{l}\text { Beta-chain of major histocompatibility complex class I } \\
\text { molecules }\end{array}$ \\
\hline Rpl/3a & ribosomal protein LI3A & Structural component of the large $60 \mathrm{~S}$ ribosomal subunit \\
\hline Hprt & hypoxanthine guanine phosphoribosyl transferase & Purine synthesis in salvage pathway \\
\hline Ywhaz & $\begin{array}{l}\text { tyrosine } 3 \text {-monooxygenase/tryptophan } 5 \text {-monooxygenase } \\
\text { activation protein, zeta polypeptide }\end{array}$ & $\begin{array}{l}\text { Signal transduction by binding to phosphorylated serine } \\
\text { residues on a variety of signalling molecules }\end{array}$ \\
\hline Sdha & Succinat dehydrogenase complex, subunit a, flavoprotein (Fp) & Electron transporter in the TCA cycle and respiratory chain \\
\hline Pgkl & phosphoglycerate kinase I & Glycolytic enzyme \\
\hline$T b p$ & TATA box binding protein & General RNA polymerase II transcription factor \\
\hline
\end{tabular}

*according to Entrez Gene database [54] 
several primer pairs (Gapdh, Actb, CypA, Pgk1 and Rpl13a) resulted in amplification products of equal size and melting temperature with genomic DNA as template, whereas the other primer pairs did not yield any signal under these conditions. Therefore, though all primer pairs (except for $A c t b)$ span introns, minus RT controls were performed for the respective primer pairs. No signals were detected in the minus RT controls. Calibration curves were generated using relative concentrations vs. the threshold cycle $(\mathrm{Ct})$. The RSq value ( $\mathrm{R}^{2}$, linear correlation coefficient), an indicator of fit for the standard curve plotted to the standard data points of all genes ranged from 0.995 to 1.000. Based on the slopes of the standard curves, the amplification efficiencies ranged from $92 \%$ to $105 \%$ (Tab. 1), (derived from the formula PCR efficiency $=101 /$ slope -1 , calculated by the Mx3005P software). Efficiencies higher than $100 \%$ may result from this calculation method, which is an overestimate of the "real efficiency" [31].

\section{Determination of the stability of housekeeping genes by GeNorm and NormFinder}

GeNorm was used to identify the most stable reference gene for each of the three analyzed time points separately. Fig. 1 shows the average expression stability values $\mathrm{M}$ of the remaining control genes. GeNorm identified CypA and Pgk1 as the most stable pairwise combination of reference genes for the experimental groups four days after ACA treatment ( $M$ value for combination of best two genes 0.145), CypA and Gapdh for the groups 7 days after the insult ( $M$ value for combination of best two genes 0.097 ) and CypA and Pgk1 for the 21 day time point (M value for combination of best two genes 0.141 ). Interestingly, for all the analyzed time points $B 2 \mathrm{~m}$ shows the highest $\mathrm{M}$ value (generated using all ten genes $0.454,4$ days; 0.531, 7 days; 0.651, 21 days). Moreover, we analyzed the pairwise variation values $(\mathrm{V})$ between two sequential normalization factors containing an increasing number of genes (Fig. 2). The pairwise variation value of $\mathrm{V} 2 / 3$ is only 0.046 for the experimental group 4 days after ACA, 0.045 for the 7 days experimental groups and 0.049 for the 21 days groups. According to Vandesompele et al. [19] the ideal pairwise variation value is less than 0.15 . Thus, although including further reference genes the $\mathrm{V}$ value further decreases, there is no need to include more than two genes into the normalization factor, because this would not improve normalization dramatically.

When NormFinder was used to analyze the same data set a slightly different order of gene stability was calculated (Tab. 3). More stable gene expression is indicated by lower average expression stability values. For the experimental groups 4 days after ACA treatment Actb was identified as the most stable gene with a stability value of 0.035 . For the groups 7 days after ACA Gapdh was calculated to be the most stable gene with a stability value of
0.032 and for 21 days $T b p$ with 0.027 . Interestingly, $B 2 m$ was identified to be the most unstable gene with stability values of $0.132,0.117$ and 0.126 at 4 days, 7 days and 21 days after ACA, respectively.

After having identified the most stable combination of two reference genes by geNorm, we calculated the expression of the other genes for each of the three different time points. Data were normalized to the normalization factor calculated by geNorm, taking into account the combination of the two best performing housekeeping genes. Most of the analyzed candidate reference genes are not significantly changed by either of the treatments at any of the three time points (Fig. 3).

In contrast, $B 2 m$ transcript, which was identified as the most unstable gene by geNorm as well as by NormFinder, is 1.7-fold upregulated in the ACA group and twofold upregulated in the ACA with minocycline treatment group 4 days after treatment compared to the sham treated group. At 21 days after treatment there is a 2.4 fold upregulation in $B 2 m$ expression in the ACA with minocycline treatment group vs. control. Though not significant, there is a trend for $B 2 m$ mRNA upregulation at 7 days after treatment too (Fig. 4).

\section{Assessment of a microglial activation marker}

Using immunohistochemistry, NeuN staining is significantly reduced due to ACA compared to sham-operated animals (Fig. 5A, B). This reflects the neuronal damage within the CA1 and dentate gyrus regions. The neuronal loss is paralleled by massive microgliosis, as demonstrated by OX42 immunostaining (Fig. 5C, D).

Moreover, in order to evaluate our experimental paradigm also via qRT-PCR, we analyzed the expression of the microglial marker Mac-1 (synonymous names $C d 11 b$ or Itgam). This gene is constitutively expressed by resting microglia as well as by macrophages and is known to be upregulated upon microglia activation [32]. We found an about 10- to 20-fold upregulation of Mac-1 four days after the ACA insult which persisted during the later time points analyzed (Fig. 6).

\section{Discussion}

The reliability of qRT-PCR data will be greatly improved by inclusion of a reference gene which passed all steps of the analysis similarly to the gene to be quantified [10]. This normalization corrects for variations caused e.g. by errors in sample quantification, RT efficiency differences or cDNA sample loading variation.

The transcription level of a good endogenous reference gene should be invariable by the different experimental conditions since the use of an unstable gene may cause 

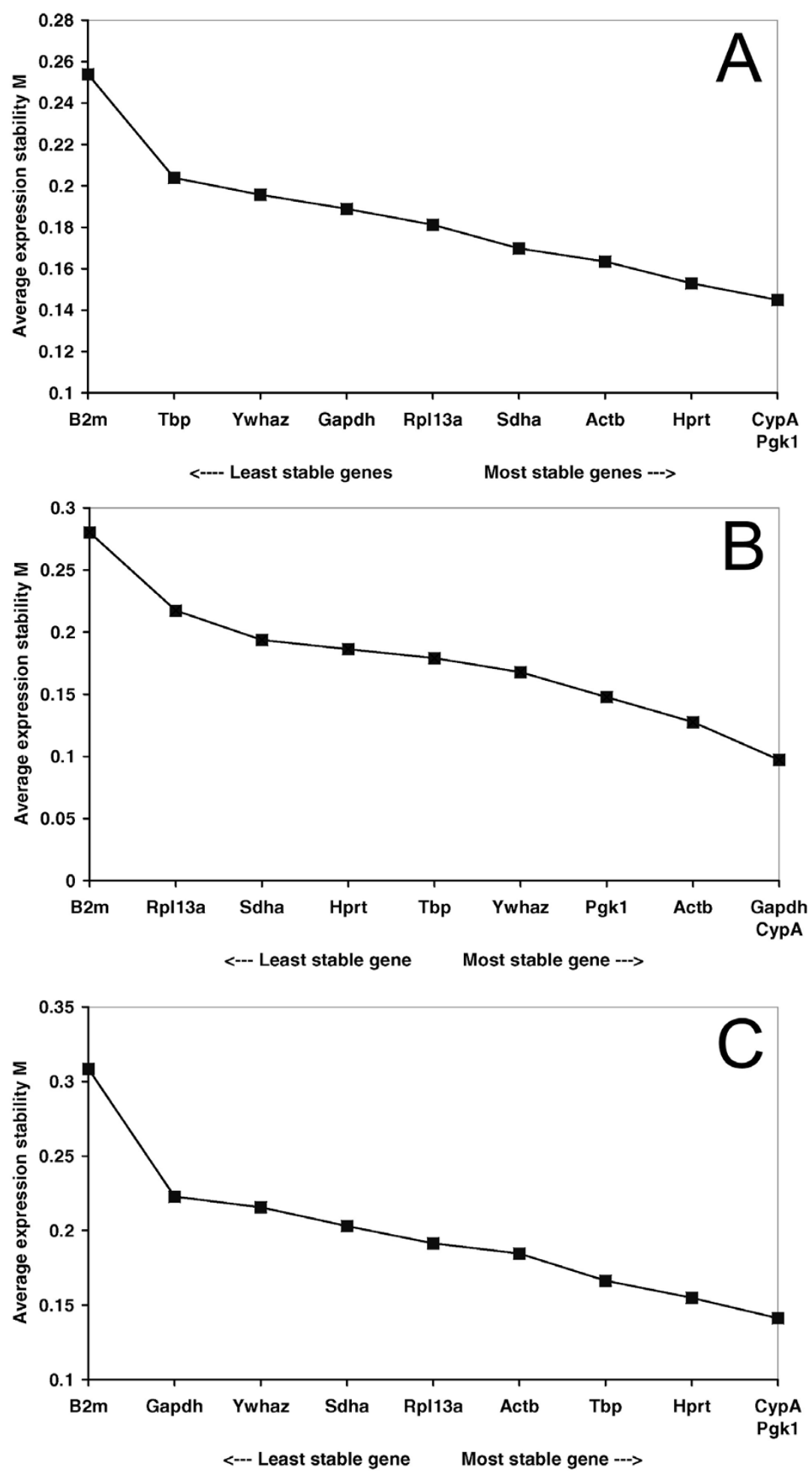

Figure I

Gene expression stability of candidate reference genes. The geNORM program was used to calculate the average expression stability values $(M)$ across all four different treatment groups together at 4 days $(A), 7$ days $(B)$ and 2 I days $(C)$ after ACA treatment. $B 2 m$ is the least stable gene (highest $M$ value) at all three time points. The combination of CypA/Pgk I, CypAl Gapdh and CypA/PgkI are the most stable genes at 4 days, 7 days and 21 days, respectively. 

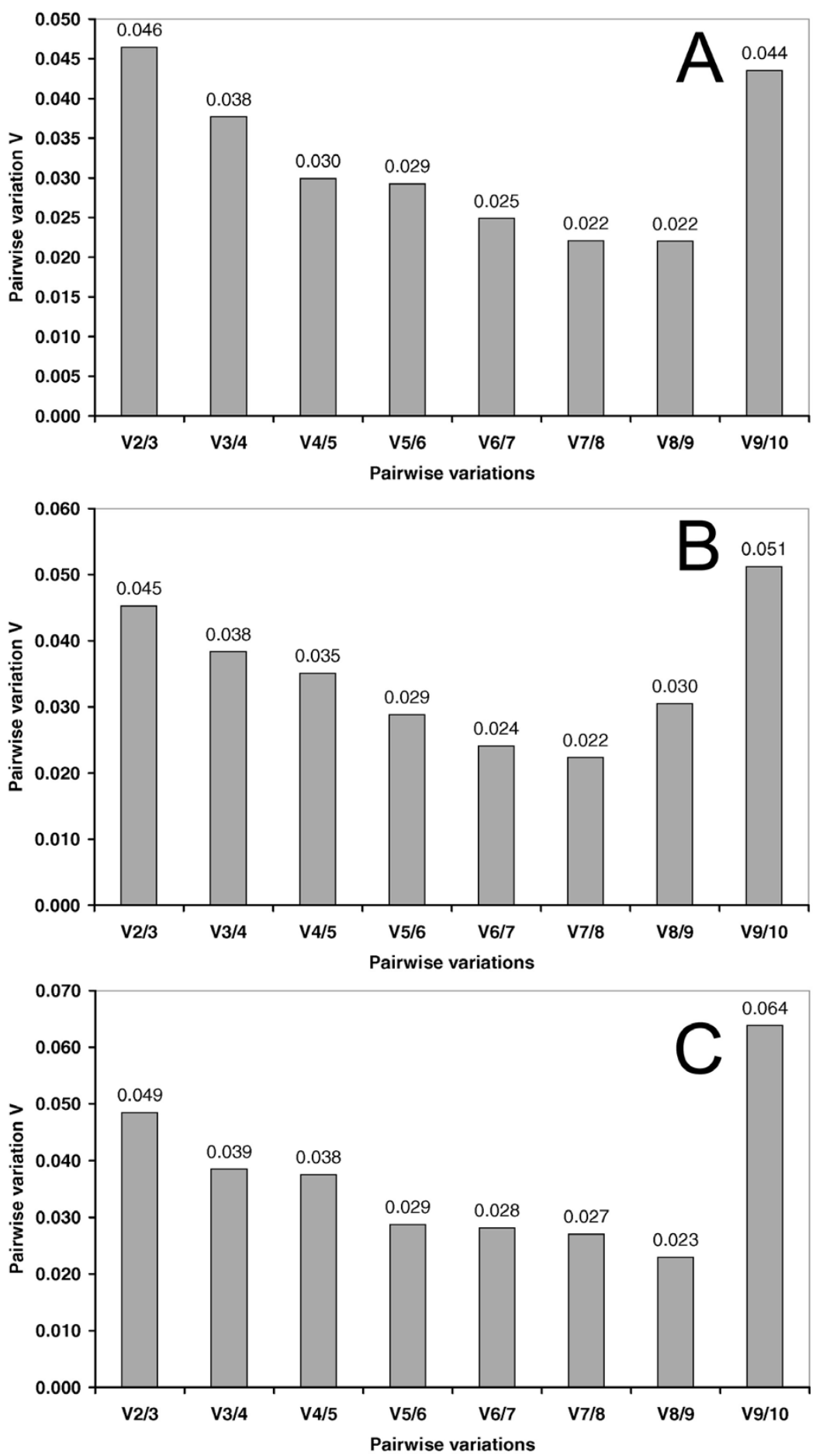

Figure 2

Determination of the optimal number of control genes. The geNORM program was used to analyze the pairwise variation between the normalization factor $\mathrm{NF}_{n}$ and $\mathrm{NF}_{n+1}$. Every bar represents change in normalization accuracy when stepwise adding more endogenous controls according to ranking in Fig. I. Data were analyzed for the three different time points 4 days (A), 7 days (B) and 2I days (C) after ACA. The use of the two most stable genes is in each case sufficient for an accurate normalization (cutoff 0.15 according to [19]). The higher $\mathrm{V} 9 / 10$ is due to the inclusion of a relative unstable gene, $\mathrm{B} 2 \mathrm{~m}$, and is in accordance with the average expression stability $M$. 
Table 3: Stability values of HKGs revealed by NormFinder

\begin{tabular}{lccc}
\hline Gene name & $4 \mathrm{~d}$ & $\mathbf{7 d}$ & $21 \mathrm{~d}$ \\
\hline Actb & $\mathbf{0 . 0 3 5}$ & 0.039 & 0.033 \\
B2m & 0.132 & 0.117 & 0.126 \\
CypA & 0.053 & 0.050 & 0.039 \\
Gapdh & 0.062 & $\mathbf{0 . 0 3 2}$ & 0.064 \\
Hprt & 0.070 & 0.061 & 0.066 \\
Pgkl & 0.057 & 0.055 & 0.048 \\
Rpl/3a & 0.049 & 0.062 & 0.039 \\
Sdha & 0.042 & 0.037 & 0.048 \\
Tbp & 0.060 & 0.036 & $\mathbf{0 . 0 2 7}$ \\
Ywhaz & 0.065 & 0.045 & 0.068 \\
Best gene & & & \\
\end{tabular}

erroneous results, either obscuring real changes or produce artificial changes of the target genes $[17,33]$.

The present study is the first detailed survey on the stability of rat housekeeping genes after a hypoxic ischemic insult due to ACA. Ten commonly used candidate reference genes were analyzed. Our observation of pseudogene-driven amplification from genomic DNA during the initial primer evaluation highlights a general need to control for these possible artifacts by including Minus RTcontrol reactions, even when intron-spanning primers are used [34].

Using NeuN immunocytochemistry, we clearly demonstrated the neuronal loss due to ACA, which is in line with earlier data, based on haematoxylin-eosin staining [3]. This is paralleled by massive microgliosis, as demonstrated by OX42 immunocytochemistry (Fig. 5). Moreover, we proved by qRT-PCR that major gene expression changes indeed occur due to the experimental treatment, since Mac-1 was found to be upregulated 10 to 20 -fold in the asphyxia groups compared to the control group (Fig. 6). Mac-1 is expressed by microglia cells, where it is known to be upregulated due to brain damage. In addition, Mac-1 is expressed by macrophages invading into the brain [32].

Concerning the candidate reference genes, our results demonstrate that variations in expression of these genes do exist. Using geNorm, CypA and Pgk1 were identified as the two most stable genes after four and 21 days, CypA and Gapdh after seven days post treatment (Fig. 1). Because this software relies on pairwise comparisons it results in a combination of the, at least, two most stable genes. The average expression stability values $M$ generated by stepwise exclusion of the most variable gene do not show a steep, but moderate decrease. This indicates that the variability of most reference gene expression levels between the samples in the experimental groups is rather small. Paralleling this, the calculated pairwise variation values $(\mathrm{V})$ for the inclusion of a third reference gene (V2/3) are $0.046,0.045$ and 0.049 at four, seven and 21 days after cardiac arrest, respectively (Fig. 2). This is well below 0.15, the threshold set by Vandesompele et al. [19], below which further adding of reference genes would not improve normalization. Thus, normalization with a combination of the two best performing genes is sufficient in our experimental setup.

Importantly, $B 2 m$ is clearly identified to be the most unstable gene for all three time points analyzed.

The alternative program, NormFinder, ranks housekeeping genes according to their expression stability using a model-based approach [11]. The program estimates both, the intra- and the inter-group expression variation and calculates candidate gene stability values. The resulting order of genes is not identical to the geNorm output, a fact that is not unexpected since both programs rely on different mathematical approaches [35]. Since the stability values of the genes ranking on the subsequent positions behind the most stable gene do not differ to a great extent, these genes are nearly as stable as the best gene. Interestingly, $B 2 m$ is identified to be the most unstable gene with NormFinder (Tab. 3). Thus, both tools clearly identify $B 2 m$ as the most variable gene in our experimental setup, which should not be used for normalization purposes in this experimental paradigm.

These results are somewhat unexpected, since hypoxic ischemic insults lead to neuronal loss, glial proliferation and the influx of leukocytes in the relevant brain regions $[36,37]$. Therefore we initially suspected that these major disturbances of the cell populations lead not only to expression changes in multiple target genes, but also to an up- or down regulation of genes that are assumed to be relatively stable in expression under normal circumstances. These genes are often referred to as housekeeping genes. Several studies, performed predominantly in different focal ischemia models, support this assumption. It has been shown, that the expression for example of Actb, Gapdh or $C y p A$, commonly used control genes, varies considerably, depending on the model used and the time points analyzed. For example, a middle cerebral artery occlusion model of focal ischemia alters Actb transcript level $[38,39]$, Gapdh mRNA amount $[40]$ or both $[41,42]$. Changes in Gapdh and Actb expression were demonstrated also in a mouse model of transient forebrain ischemia [43] as well as in a rat model of global cerebral ischemia [44] using microarrays. Contradictory to the above findings, reporting variations in housekeeping gene expression after various ischemic insults, Meldgaard et al. [45] demonstrated Gapdh as well as Hprt to be reasonable sta- 

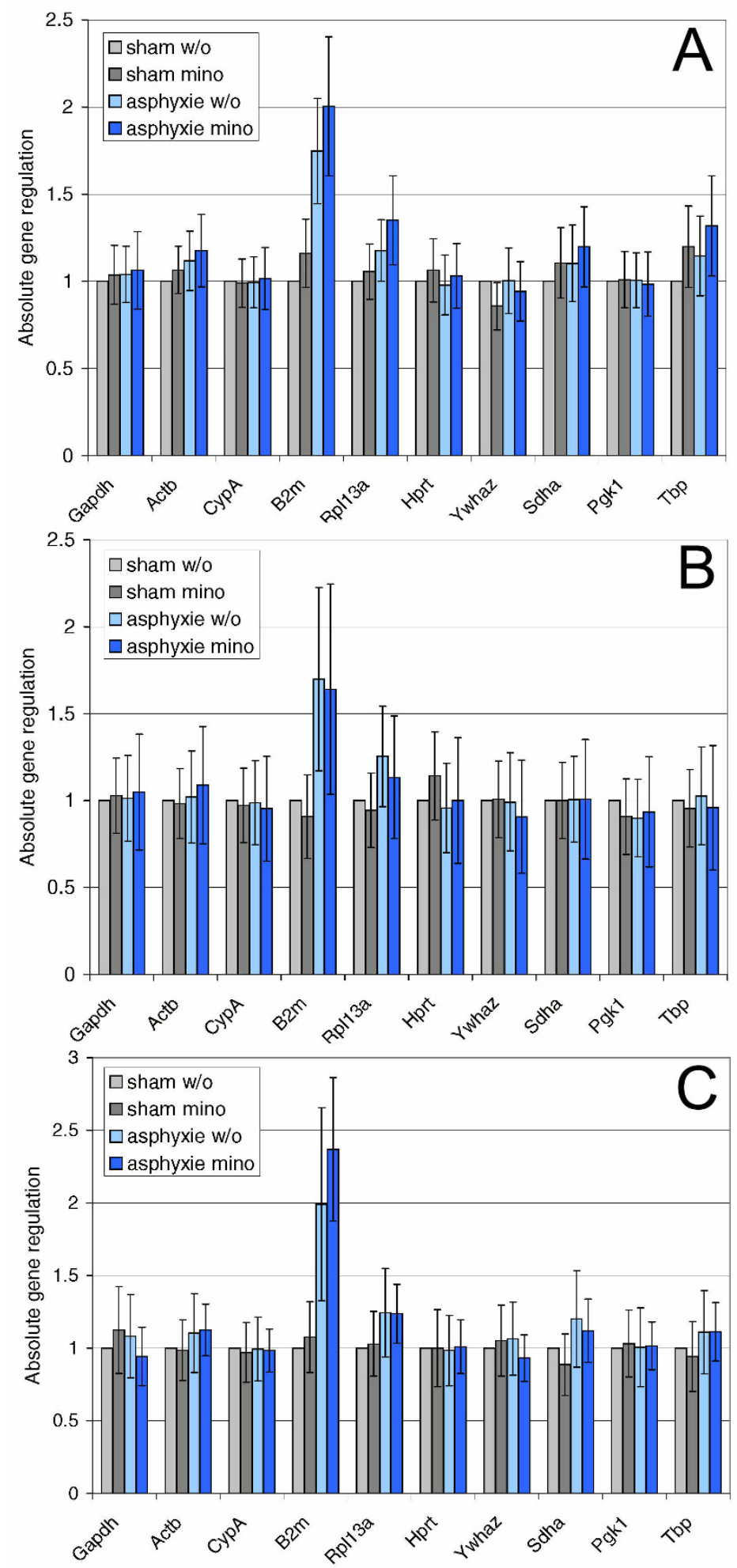

Figure 3

Expression analysis of ten potential reference genes in the ACA model. Expression ratios were calculated using REST-MCS. The absolute gene regulation values along with the corresponding standard error were used to create the graph. The control group, i.e. sham operated, was assigned a value of I. 

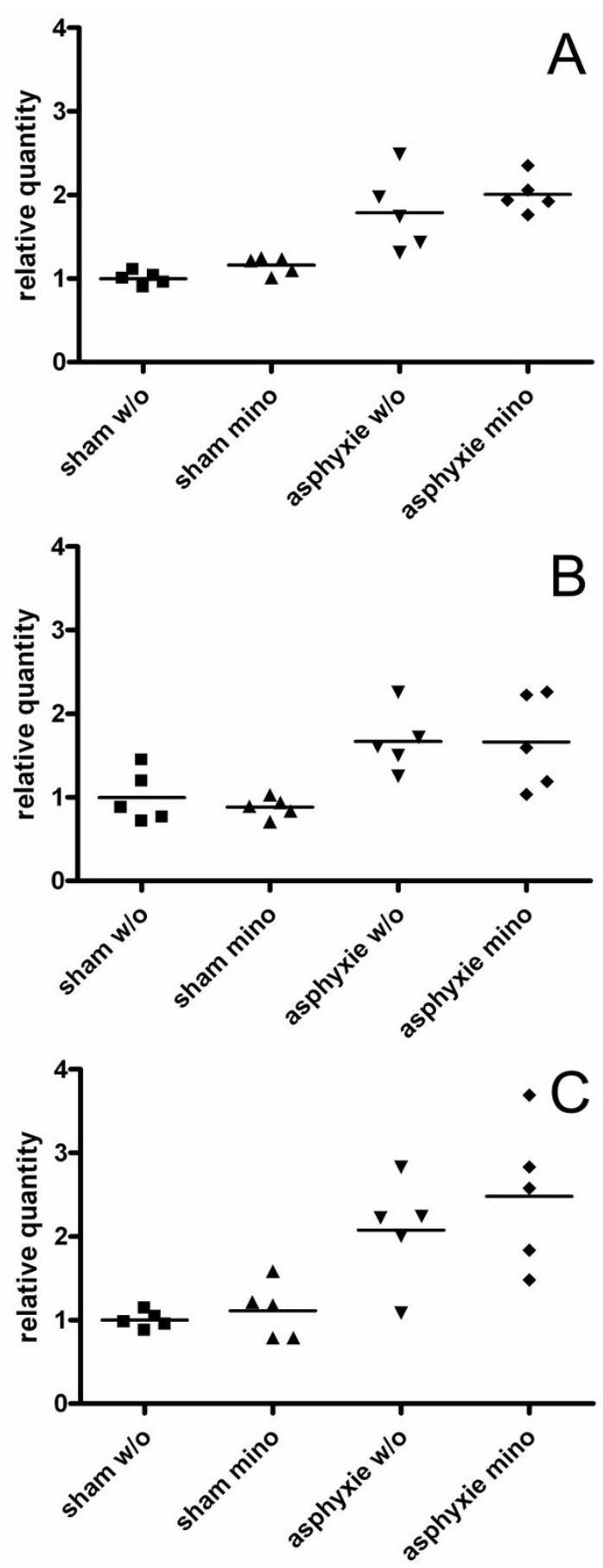

Figure 4

$B 2 m$ is unsuitable as an endogenous control gene after ACA treatment. Scatterplots showing $B 2 m$ mRNA levels in the different treatment groups. $32 m$ expression in hippocampus is upregulated due to asphyxial cardiac arrest 4 days $(A)$ and 21 days $(C)$ after treatment. Though not significant, there is a tendency for $B 2 m$ upregulation 7 days after $A C A$ too (B). Compared to the sham treated group $B 2 m$ expression is $1.7 \pm 0.30$-fold upregulated in the ACA group ( $p$-value 0.038$)$ and $2.0 \pm 0.39$ fold upregulated in the ACA with minocycline treatment group ( $p$-value 0.009), respectively four days after the injury. Twentyone days after treatment $B 2 m$ is $2.4 \pm 0.49$-fold upregulated in the ACA with minocycline treatment group ( $p$-value 0.020 ) vs. sham operated group. Absolute gene regulation value, standard error and $p$-value are given as calculated using REST-MCS software. 

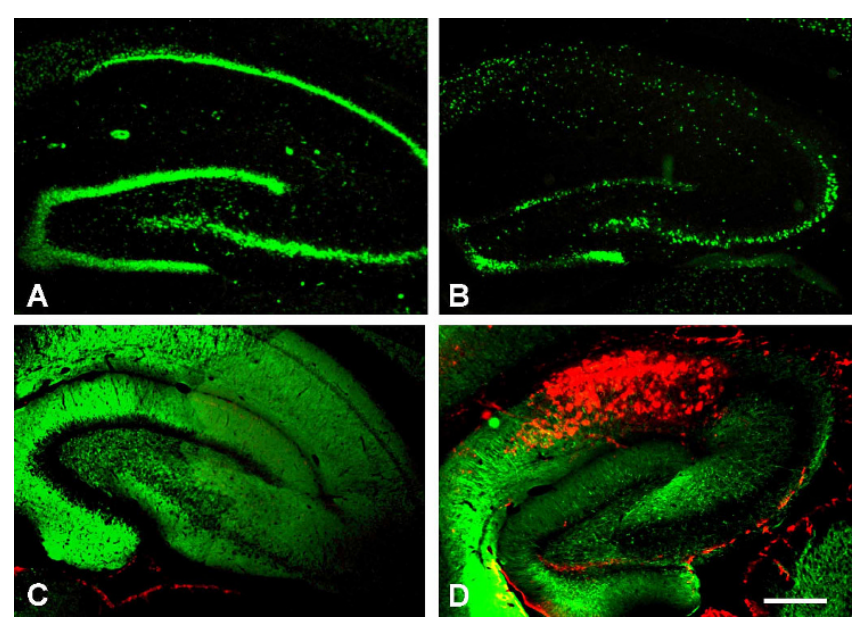

Figure 5

Immunofluorescence staining of the hippocampus. In sham-operated animals (A), the hippocampus appeared intact on NeuN immunostaining 21 day post insult. Asphyxiaexposed animals (B), however, showed a significant decrease of NeuN immunopositive cells, particularly prominent in the CAI and dentate gyrus regions. In parallel, OX42-immunocytostaining (red) revealed a massive microgliosis in the CAI region (D) when compared to sham-operated animals (C). C, D: MAP2 counter stained, bar $=400 \mu \mathrm{m}$.

ble in four neurological disease models. Altogether, this demonstrates that a careful screen for reliable reference genes is indispensable for each individual experimental situation.

It is interesting to note, that the spread of data points originating from the individual animals is much wider for Mac-1 as well as $B 2 m$ in the asphyxia groups, than for the other analyzed genes in all experimental groups (Figs. 4, 6). Mac-1, the microglia marker is clearly upregulated, mirroring activation/proliferation of these cells in the injured brain after ACA. However, as seen by the spread of data points, the extent of upregulation differs markedly between the individuals. One may speculate that each animal performs slightly different to the ACA procedure, for example due to the individuality in the vascular network of the brain. This may lead to the gradually different extent of gene expression changes of regulated genes, whereas unregulated genes do not show this variation.

\section{Conclusion}

Taken together, our data provide a guideline helping to choose reference genes for the analysis of long term gene expression changes due to ACA. Our results suggest the use of the geometric mean of $C y p A$ and Pgk1 four and 21 days after treatment and CypA and Gapdh at seven days, respectively. These combinations seem appropriate for the detection of slight changes. On the other hand, due to higher costs and efforts using more than one reference gene in multiple samples, only a single reference gene may be preferred. This decision depends on the degree of accuracy required. Based on our data, $C y p A$ could best be used as an internal reference gene under such circumstances. Furthermore, our data confirm that suitable reference genes are highly specific for a particular experimental situation, thus requiring a careful evaluation for every individual experimental setup.

\section{Methods}

\section{Asphyxial cardiac arrest model}

All animals were maintained in accordance with the guidelines of the German Animal Welfare Act. The study was approved by the Animal Care and Use Committees of the State of Saxony-Anhalt and the University of Magdeburg under the permit number $\mathrm{G} / 1 / 06$. The animals were housed under temperature -controlled conditions at $21 \pm$ $1{ }^{\circ} \mathrm{C}$, a $12 \mathrm{~h} \mathrm{light/dark} \mathrm{cycle,} \mathrm{and} \mathrm{free} \mathrm{access} \mathrm{to} \mathrm{standard} \mathrm{rat}$ chow (Altromin 1324 $4^{\mathrm{TM}}$, Altromin GmbH, Lage, Germany) and water.

Sixty age-matched (15 weeks, 300-350 g) and strainmatched (Wistar, inbred, Harlan-Winkelmann; Borchen, Germany) male rats were divided into four treatment groups: (i) asphyxial cardiac arrest (ACA); (ii) ACA with minocycline treatment; (iii) sham operated; (iv) sham operated, with minocycline treatment. Three different survival times were analyzed per group: 4 days, 7 days and 21 days. Thus, 5 animals were used per treatment and time point.

The surgery protocol has been described in detail previously by Ebmeyer et al. [3] with the slight modification that resuscitation was started exactly after $5 \mathrm{~min}$ of asphyxiation. During preparation, the insult and the first hour post return of spontaneous circulation (ROSC) body temperature was controlled and maintained at $37^{\circ} \mathrm{C}$. Rats were then further kept at normal body temperature $\left(37^{\circ} \mathrm{C}\right)$ by placing them in an incubator cage for $24 \mathrm{~h}$ post-resuscitation. Blood pressure values were measured according to the protocol. The mean artery pressure (MAP) values were similar in all animals included in the study and the course over time closely resembled the published data for intra-insult temperature-controlled Wistar rats [3]. Animals that showed critical low blood pressure levels (MAP $<50 \mathrm{mmHg}$ ) were excluded from further analysis.

Minocycline hydrochloride (Sigma, St. Louis, USA) was administered twice a day, i.p., at a dosage of 6 mg every 12 hours for a period of 5 days. First minocycline injection was performed $60 \mathrm{~min}$ after ROSC. The drug was dissolved in PBS at a concentration of $6 \mathrm{mg} / \mathrm{ml}$. Between the injections the solution was stored at $6^{\circ} \mathrm{C}$ for five days. The 

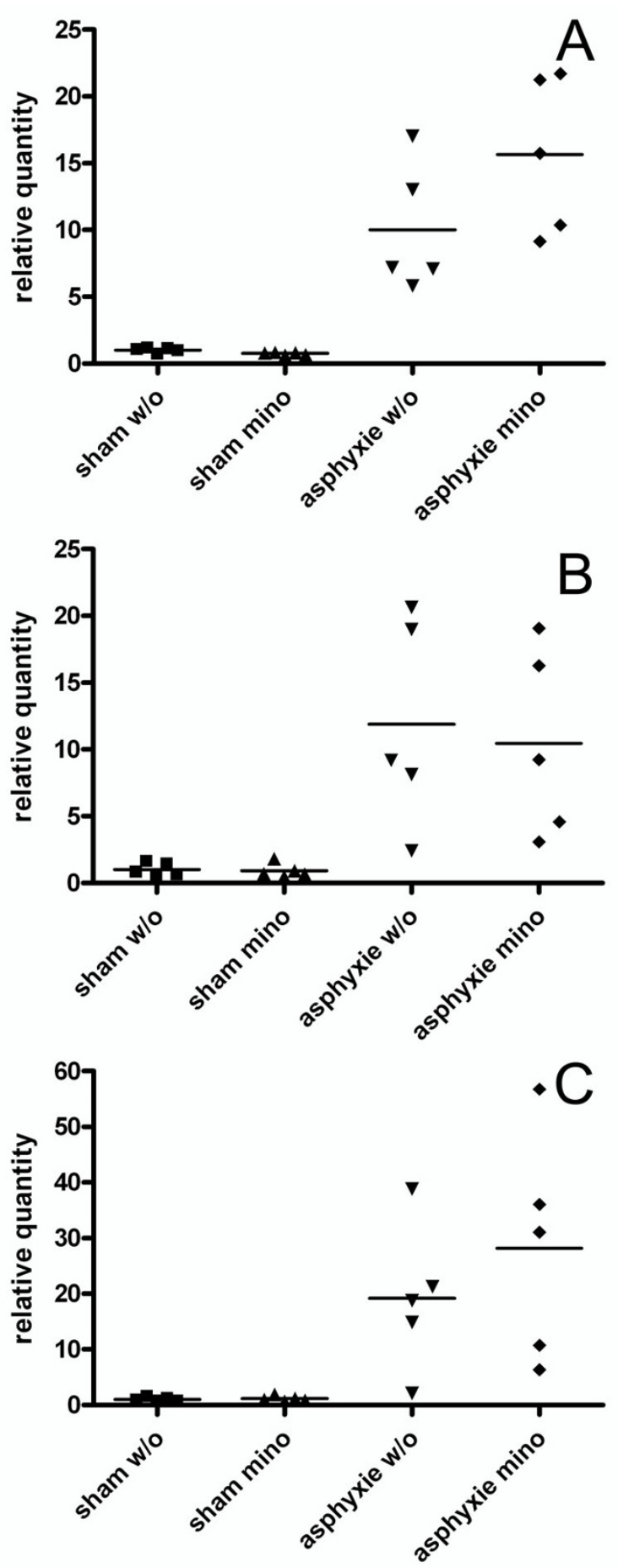

\section{Figure 6}

Mac- $I$ is upregulated after ACA treatment. Scatterplots showing Mac-I mRNA levels in the different treatment groups. Compared to the sham treated group the expression of the microglia marker Mac- $I$ is $9.3 \pm 2.34$-fold upregulated four days after the insult in the asphyxial cardiac arrest group ( $\mathrm{p}$-value 0.006) and 14.9 \pm 4.56 -fold in the ACA with minocycline treatment group ( $p$-value $0.00 \mathrm{I}$ ) (A). Seven days after treatment Mac-I is $10.3 \pm 6.18$-fold ( $p$-value $0.0 \mathrm{II}$ ) and $9.2 \pm 4.84$-fold ( $\mathrm{p}$ value 0.001 ) upregulated in the ACA and in the ACA with minocycline treatment groups, respectively (B). The increased Mac$I$ expression is detectable $2 I$ days after the insult too (I4.3 \pm 9.17 -fold, $p$-value 0.024 and $22.2 \pm 9.93$-fold, $p$-value 0.006$)$ in the ACA and ACA with minocycline treatment groups, respectively $(C)$. Calculations were done using REST-MCS software. 
volume to be injected was adapted to room temperature before the injection. Sham operated animals received a PBS injection $(1 \mathrm{ml})$.

Rats were sacrificed by decapitation during deep anesthesia. Brains were quickly removed and, for qRT-PCR, hippocampus was dissected on ice, immediately frozen on dry ice and stored at $-80^{\circ} \mathrm{C}$ until RNA extraction.

\section{Immunohistochemistry}

For immunohistochemistry, brains were quickly removed from the cranium, postfixed in $4 \%$ buffered paraformaldehyde (pH 7.4) at $4{ }^{\circ} \mathrm{C}$ overnight, cryoprotected in a solution of $30 \%$ sucrose (Merck) in $0.4 \%$ buffered paraformaldehyde ( $\mathrm{pH}$ 7.4) for 2 days and rapidly frozen at $20^{\circ} \mathrm{C}$ using 2-methylbutan (Roth, Karlsruhe, Germany). Serial sagittal sections ( $20 \mu \mathrm{m}$ thick) were cut on a cryostat (Jung Frigocut 2800 E, Leica, Bensheim, Germany). Freefloating sections were washed and incubated with monoclonal mouse anti-NeuN (Chemicon, Temecula, CA, 1:100), polyclonal rabbit anti-MAP 2 (microtubule-associated protein 2, Chemicon 1:2.500), or monoclonal mouse anti-CD 11b/c (OX42, PharMingen, Hamburg, Germany, 1:800) in PBS with $0.3 \%$ Triton X-100 and $1 \%$ normal goat serum overnight at $4{ }^{\circ} \mathrm{C}$. Following incubation with primary antibodies, slices were washed in PBS (3 $\times 5 \mathrm{~min}$ ), and incubated overnight with the respective secondary antibodies (1:500, goat anti-mouse-IgG Alexa Fluor 488, goat anti-rabbit-IgG Alexa Fluor 488, goat antimouse-IgG Alexa Fluor 546, Molecular Probes, Göttingen, Germany), mounted and examined on a fluorescence microscope (Axiophot, Zeiss). Control reactions (substitution of the primary antisera by phosphate buffered saline) yielded negative results (i.e. no specific immunostaining was seen in these sections).

\section{Reference gene selection and primer design}

Candidate reference genes were selected from those most commonly used in the literature. To reduce the chance that these genes might be coregulated, ten genes belonging to different functional classes were selected. Primers for Actb, CypA and Hprt were as published by Peinnequin et al. [46]. Mac-1 primers were as published by Raghavendra et al. [47]. All other primers were designed by the primer 3 software [48] based on rat sequences in the database [49]. Here primers were chosen, that bind to different exons in order to avoid non-specific product formation from potentially contaminating genomic DNA. The specificity of the primers was checked using a BLAST search against nucleotide collection (nr) of the NCBI database.

All primers were synthesized by MWG Biotech (Ebersberg, Germany). The sequences of primers are listed in Tab. 1.

\section{RNA isolation and reverse transcription}

Hippocampal tissue was homogenized in peqGOLD TriFast (Total RNA Isolation Reagent, PeqLab, Erlangen, Germany) using an Ultra-Turrax Homogenizer (IKA Labortechnik, Staufen i. Br., Germany). Total RNA was prepared according to the manufacturers instructions. The concentration of total RNA was determined by measuring the optical density at $260 \mathrm{~nm}$ and the purity was checked as the $260 \mathrm{~nm} / 280 \mathrm{~nm}$ ratio with expected values between 1.8 and 2.0. The integrity of total RNA was assessed by electrophoresis on $1.2 \%(\mathrm{w} / \mathrm{v})$ agarose gels. To remove potential DNA contamination, the RNA samples were DNase treated (TURBO DNA-free Kit, Ambion, Austin, USA). First strand cDNA was prepared from $1 \mu \mathrm{g}$ DNase treated total RNA in a total volume of $20 \mu \mathrm{l}$ using the RevertAid First Strand cDNA Synthesis Kit (Fermentas, St. Leon-Roth, Germany). Oligo(dT $)_{18}$ primers were used and all samples were stored at $-80^{\circ} \mathrm{C}$ until further analysis. Additionally, cDNA was prepared from a mixed RNA sample (later referred to as pool cDNA) for each of the tree time points. For this purpose equal amounts of DNase treated total RNA of all twenty samples of each time point were mixed. Moreover, minus RT controls were prepared for each sample using the identical procedure except for the omission of the enzyme.

\section{Real-time PCR}

The real-time PCR was performed using the MX3005P device (Stratagene, La Jolla, CA, USA). The reactions contained 1× Brilliant SYBR Green QPCR Master Mix (Stratagene), $30 \mathrm{nM}$ ROX reference dye, each primer at $200 \mathrm{nM}$ and prediluted cDNA (according to $10 \mathrm{ng}$ total RNA) in a $25 \mu \mathrm{l}$ reaction. After an initial denaturation step at $95^{\circ} \mathrm{C}$ for $10 \mathrm{~min}$ amplification was performed with 40 cycles of denaturation at $95^{\circ} \mathrm{C}$ for $30 \mathrm{~s}$, annealing at $60^{\circ} \mathrm{C}$ for $40 \mathrm{~s}$ and extension at $72^{\circ} \mathrm{C}$ for $40 \mathrm{~s}$. Amplification was followed by a melting curve analysis to confirm PCR product specificity.

No signals were detected in no-template controls. Minus RT controls were run for those primer pairs, that have been shown to give a PCR product of same size and melting temperature in initial test experiments with genomic DNA (0.1-50 ng/well). No signals were detected in the minus RT controls.

The experimental threshold $(\mathrm{Ct})$ was calculated using the algorithm enhancements provided by the MxPro Mx3005P v3.00 software: amplification based threshold, adaptive baseline, moving average. All samples were run in duplicate and the mean value of each duplicate was used for all further calculations.

During optimization of the protocol PCR products were loaded on $2 \%$ agarose gels to confirm specificity of ampli- 
fication and the absence of primer dimer formation. PCR efficiencies were estimated by running standard curves with the above described pool cDNA ( 5 points, cDNA amount between $25 \mathrm{ng}$ and $0.04 \mathrm{ng}$ according to initial total RNA concentration).

\section{Determination of reference gene expression stability}

Two publicly available software tools, geNorm [19] and NormFinder [11] were used to analyze gene expression stability. Both tools require the transformation of Ct values to linear scale expression quantities. The average $\mathrm{Ct}$ values of the duplicates were therefore exported into Microsoft Excel from the Mx3005P software. Ct values were converted into relative quantities $(\mathrm{Q})$ via the delta$\mathrm{Ct}$ method by the formula $\mathrm{Q}=(\mathrm{E}) \mathrm{dCt}$, with $\mathrm{dCt}=\mathrm{Ct}$ of the highest abundant sample-Ct of the sample and E (efficiency) as determined by linear regression (calculated by the Mx3005P software). The quantities were then imported into geNorm software [50] (version 3.4), which was used as described in its manual. Twenty data points were used per time point (five biological replicates per treatment). Each of the three time points was analyzed separately. GeNorm calculates a gene-stability measure M, which is the average pairwise variation of a particular gene with all other control genes. Genes are ranked according to the determined $M$ value from the least stable (highest $M$ value) to the most stable (lowest $M$ value).

Moreover, the calculated quantities were entered into a second software tool, NormFinder [51]. NormFinder estimates the overall expression variation of the candidate normalization genes and the variation between sample subgroups of the sample set using a model-based approach [11]. According to the resulting stability value the candidate reference genes can be ranked based on their expression stability.

A workflow diagram schematically depicting the process of stable gene selection is provided (Additional file 1).

\section{Calculation of the expression ratio of candidate reference} genes in the different treatment groups versus control The relative expression software tool $\left(\mathrm{REST}^{\circ}\right)[52,53]$ was adopted to calculate expression ratios. This software allows for a group-wise comparison of expression differences. Moreover, the expression ratio results are tested for significance by a Pair Wise Fixed Reallocation Randomisation Test ${ }^{\bullet}$. Out of the several software versions, REST-MCS was chosen, because this allows the comparison of up to six experimental conditions against one reference condition for up to ten samples per group. Each of the three time points was analyzed separately. The experimental group (iii), i.e. sham operated, served as the reference condition. The two most stable genes, as calculated in advance by geNorm, were set as reference genes. The abso- lute gene regulation values along with the corresponding standard error, calculated by the REST-MCS software, were then forwarded to Microsoft Excel to create the graph presented in Fig. 3. For comparison, the reference condition, i.e. sham operated, was assigned a value of 1 .

\section{Calculation of the relative expression of $\mathrm{B} 2 \mathrm{~m}$ and Mac- I in the different treatment groups}

Ct values were converted into relative quantities $(\mathrm{Q})$ via the delta-Ct method by the formula $\mathrm{Q}=(\mathrm{E})^{\mathrm{dCt}}$, with $\mathrm{dCt}=$ $\mathrm{Ct}$ of the highest abundant sample-Ct of the sample and $\mathrm{E}$ (efficiency). Relative quantities were normalized by dividing by the normalization factor calculated by geNorm from the two most stable genes. Normalized relative quantities were then rescaled by dividing by the arithmetic mean of the normalized relative quantities of the control group (sham w/o). The calculated values were imported into Prism 4 program (GraphPad Software, Inc., San Diego, CA) to generate the scatterplots presented in Fig. 4 and Fig. 6 .

\section{Authors' contributions}

KL designed and performed the qPCR experiments, was responsible for data analyses and writing the manuscript. $\mathrm{RJ}$ and HS carried out all animal surgery, minocycline treatment, including tissue sampling. They participated in RNA purification. UE primarily established the ACA experimental model and supervised RJ and HS in surgery. GK conceived the study, performed the immunohistochemistry and critically reviewed the manuscript. All authors read and approved the final manuscript.

\section{Additional material}

\section{Additional file 1}

Workflow schema for reference gene selection. The diagram illustrates the process of stable gene selection for normalization purposes in relative quantification. Workflow is given for two software programs, geNorm and NormFinder. The scheme is based on $[11,19]$ as well as the accompanying software manuals $[55,56]$. For the principle of these programs see $[11,19]$. Transformation of raw Ct values into quantities can alternatively be performed using standard curves. The use of five to ten candidate reference genes is strongly recommended [56]. (HKG: Abbr. housekeeping gene).

Click here for file

[http://www.biomedcentral.com/content/supplementary/14712199-9-53-S1.pdf]

\section{Acknowledgements}

The authors wish to thank Regina Dobrowolny and Leona Bück for excellent technical assistance, and Dr. Peter Kreutzmann for helpful discussions.

\section{References}

I. Cole SL, Corday E: Four-minute limit for cardiac resuscitation. J Am Med Assoc 1956, I 6 I:| |454-| 458. 
2. Safar P: Cerebral resuscitation after cardiac arrest: a review. Circulation 1986, 74:IVI38-I53.

3. Ebmeyer U, Keilhoff G, Wolf G, Rose W: Strain specific differences in a cardio-pulmonary resuscitation rat model. Resuscitation 2002, 53:189-200.

4. Hicks SD, DeFranco DB, Callaway CW: Hypothermia during reperfusion after asphyxial cardiac arrest improves functional recovery and selectively alters stress-induced protein expression. J Cereb Blood Flow Metab 2000, 20:520-530.

5. Hickey RW, Zhu RL, Alexander HL, Jin KL, Stetler RA, Chen J, Kochanek PM, Graham SH: 10 kD mitochondrial matrix heat shock protein mRNA is induced following global brain ischemia in the rat. Brain Res Mol Brain Res 2000, 79:169-173.

6. Katz LM, Lotocki G, Wang Y, Kraydieh S, Dietrich WD, Keane RW: Regulation of caspases and XIAP in the brain after asphyxial cardiac arrest in rats. Neuroreport 200I, I 2:375I-3754.

7. Li ZP, Chen SQ, Wang SS, Huang WJ, Cheng JY, Wang W, Wang WT, Tan YX: [Expression of mRNA of matrix metalloproteinase and tissue inhibitor of matrix metalloproteinase after cardiopulmonary resuscitation for asphyxial cardiac arrest in rat]. Zhongguo Wei Zhong Bing Ji Jiu Yi Xue 2005, I 7:548-55 I.

8. Vosler PS, Logue ES, Repine MJ, Callaway CW: Delayed hypothermia preferentially increases expression of brain-derived neurotrophic factor exon III in rat hippocampus after asphyxial cardiac arrest. Brain Res Mol Brain Res 2005, I35:2I-29.

9. D'Cruz BJ, Fertig KC, Filiano AJ, Hicks SD, DeFranco DB, Callaway $\mathrm{CW}$ : Hypothermic reperfusion after cardiac arrest augments brain-derived neurotrophic factor activation. J Cereb Blood Flow Metab 2002, 22:843-85।.

10. Huggett J, Dheda K, Bustin S, Zumla A: Real-time RT-PCR normalisation; strategies and considerations. Genes Immun 2005, 6:279-284

II. Andersen CL, Jensen JL, Orntoft TF: Normalization of real-time quantitative reverse transcription-PCR data: a model-based variance estimation approach to identify genes suited for normalization, applied to bladder and colon cancer data sets. Cancer Res 2004, 64:5245-5250.

12. Bustin SA: Quantification of mRNA using real-time reverse transcription PCR (RT-PCR): trends and problems. J Mol Endocrinol 2002, 29:23-39.

13. Bonefeld BE, Elfving B, Wegener G: Reference genes for normalization: A study of rat brain tissue. Synapse 2008, 62:302-309.

14. Ohl F, Jung M, Radonic A, Sachs M, Loening SA, Jung K: Identification and validation of suitable endogenous reference genes for gene expression studies of human bladder cancer. J Uro 2006, 175:1915-1920.

15. Pombo-Suarez M, Calaza M, Gomez-Reino JJ, Gonzalez A: Reference genes for normalization of gene expression studies in human osteoarthritic articular cartilage. BMC Mol Biol 2008, 9:17.

16. Infante C, Matsuoka MP, Asensio E, Canavate JP, Reith M, Manchado $M$ : Selection of housekeeping genes for gene expression studies in larvae from flatfish using real-time PCR. BMC Mol Biol 2008, 9:28.

17. Dheda K, Huggett JF, Chang JS, Kim LU, Bustin SA, Johnson MA, Rook GA, Zumla $A$ : The implications of using an inappropriate reference gene for real-time reverse transcription PCR data normalization. Anal Biochem 2005, 344:14I-I43.

18. Dheda K, Huggett JF, Bustin SA, Johnson MA, Rook G, Zumla A: Validation of housekeeping genes for normalizing RNA expression in real-time PCR. Biotechniques 2004, 37: | |2-1 |4. 1 16, I I8119

19. Vandesompele J, De Preter K, Pattyn F, Poppe B, Van Roy N, De Paepe A, Speleman F: Accurate normalization of real-time quantitative RT-PCR data by geometric averaging of multiple internal control genes. Genome Biol 2002, 3:RESEARCH0034.

20. Smilack JD: The tetracyclines. Mayo Clin Proc 1999, 74:727-729.

21. Blum D, Chtarto A, Tenenbaum L, Brotchi J, Levivier M: Clinical potential of minocycline for neurodegenerative disorders. Neurobiol Dis 2004, 17:359-366.

22. Yong VW, Wells J, Giuliani F, Casha S, Power C, Metz LM: The promise of minocycline in neurology. Lancet Neurol 2004, 3:744-75I.

23. Stirling DP, Koochesfahani KM, Steeves JD, Tetzlaff W: Minocycline as a neuroprotective agent. Neuroscientist 2005, I I:308-322.
24. Elewa HF, Hilali H, Hess DC, Machado LS, Fagan SC: Minocycline for short-term neuroprotection. Pharmacotherapy 2006, 26:5I5-52।

25. Yrjanheikki J, Tikka T, Keinanen R, Goldsteins G, Chan PH, Koistinaho J: A tetracycline derivative, minocycline, reduces inflammation and protects against focal cerebral ischemia with a wide therapeutic window. Proc Natl Acad Sci USA 1999, 96:13496-13500.

26. Xu L, Fagan SC, Waller JL, Edwards D, Borlongan CV, Zheng J, Hill WD, Feuerstein G, Hess DC: Low dose intravenous minocycline is neuroprotective after middle cerebral artery occlusionreperfusion in rats. $B M C$ Neurol 2004, 4:7.

27. Wang CX, Yang T, Shuaib A: Effects of minocycline alone and in combination with mild hypothermia in embolic stroke. Brain Res 2003, 963:327-329.

28. Weng YC, Kriz J: Differential neuroprotective effects of a minocycline-based drug cocktail in transient and permanent focal cerebral ischemia. Exp Neurol 2007, 204:433-442.

29. Koistinaho M, Malm TM, Kettunen MI, Goldsteins G, Starckx S, Kauppinen RA, Opdenakker G, Koistinaho J: Minocycline protects against permanent cerebral ischemia in wild type but not in matrix metalloprotease-9-deficient mice. J Cereb Blood Flow Metab 2005, 25:460-467.

30. Zhang Z, Harrison PM, Liu Y, Gerstein M: Millions of years of evolution preserved: a comprehensive catalog of the processed pseudogenes in the human genome. Genome Res 2003, I3:254|-2558.

31. Bustin SA: $A-Z$ of quantitative $P C R$ I edition. La Jolla: International University Line, CA, USA; 2004.

32. Stoll G, Jander $S$ : The role of microglia and macrophages in the pathophysiology of the CNS. Prog Neurobiol 1999, 58:233-247.

33. Ropenga A, Chapel A, Vandamme M, Griffiths NM: Use of reference gene expression in rat distal colon after radiation exposure: a caveat. Radiat Res 2004, 161:597-602.

34. Mutimer H, Deacon N, Crowe S, Sonza S: Pitfalls of processed pseudogenes in RT-PCR. Biotechniques 1998, 24:585-588.

35. Willems E, Mateizel I, Kemp C, Cauffman G, Sermon K, Leyns L: Selection of reference genes in mouse embryos and in differentiating human and mouse ES cells. Int J Dev Biol 2006, 50:627-635.

36. Lipton P: Ischemic cell death in brain neurons. Physiol Rev 1999 , 79: $|43|-\mid 568$.

37. Wang $\mathrm{Q}$, Tang $\mathrm{XN}$, Yenari MA: The inflammatory response in stroke. J Neuroimmunol 2007, 184:53-68.

38. Bemeur C, Ste-Marie L, Desjardins P, Hazell AS, Vachon L, Butterworth R, Montgomery J: Decreased beta-actin mRNA expression in hyperglycemic focal cerebral ischemia in the rat. Neurosci Lett 2004, 357:21।-2/4.

39. Harrison DC, Medhurst AD, Bond BC, Campbell CA, Davis RP, Philpott KL: The use of quantitative RT-PCR to measure mRNA expression in a rat model of focal ischemia - caspase-3 as a case study. Brain Res Mol Brain Res 2000, 75: I43-149.

40. Lennmyr F, Terent A, Syvanen AC, Barbany G: Vascular endothelial growth factor gene expression in middle cerebral artery occlusion in the rat. Acta Anaesthesiol Scand 2005, 49:488-493.

4I. Tian YF, Zhang PB, Xiao XL, Zhang JS, Zhao II, Kang OY, Chen XL, Qiu F, Liu Y: The quantification of ADAMTS expression in an animal model of cerebral ischemia using real-time PCR. Acta Anaesthesiol Scand 2007, 5I:I 58-164.

42. Bond BC, Virley DJ, Cairns NJ, Hunter AJ, Moore GB, Moss SJ, Mudge $A W$, Walsh FS, Jazin E, Preece P: The quantification of gene expression in an animal model of brain ischaemia using TaqMan real-time RT-PCR. Brain Res Mol Brain Res 2002, 106: I0I-II6.

43. Nishida $Y$, Sugahara-Kobayashi M, Takahashi Y, Nagata T, Ishikawa K, Asai S: Screening for control genes in mouse hippocampus after transient forebrain ischemia using high-density oligonucleotide array. J Pharmacol Sci 2006, I0 I:52-57.

44. Kobayashi MS, Takahashi Y, Nagata T, Nishida Y, Murata A, Ishikawa $\mathrm{K}$, Asai S: Screening for control genes in rat global cerebral ischemia using high-density oligonucleotide array. J Neurosci Res 2004, 76:5।2-5 I8.

45. Meldgaard M, Fenger C, Lambertsen KL, Pedersen MD, Ladeby R, Finsen B: Validation of two reference genes for mRNA level studies of murine disease models in neurobiology. J Neurosci Methods 2006, I56:101-110. 
46. Peinnequin A, Mouret C, Birot O, Alonso A, Mathieu J, Clarencon D, Agay D, Chancerelle Y, Multon E: Rat pro-inflammatory cytokine and cytokine related mRNA quantification by real-time polymerase chain reaction using SYBR green. BMC Immunol 2004, 5:3.

47. Raghavendra V, Tanga FY, DeLeo JA: Complete Freunds adjuvant-induced peripheral inflammation evokes glial activation and proinflammatory cytokine expression in the CNS. Eur J Neurosci 2004, 20:467-473.

48. Rozen S, Skaletsky H: Primer3 on the WWW for general users and for biologist programmers. Methods Mol Biol 2000, 132:365-386.

49. GenBank [http://www.ncbi.nlm.nih.gov/Genbank/]

50. geNorm [http://medgen.ugent.be/ jvdesomp/genorm/]

51. NormFinder [http://www.mdl.dk/publicationsnormfinder.htm]

52. Relative expression software tool (REST) [http://rest.genequantification.info]

53. Pfaffl MW, Horgan GW, Dempfle L: Relative expression software tool (REST) for group-wise comparison and statistical analysis of relative expression results in real-time PCR. Nucleic Acids Res 2002, 30:e36.

54. Entrez Gene [http://www.ncbi.nlm.nih.gov/sites/entrez]

55. geNorm software manual [http://medgen.ugent.be/ jivdesomp/ genorm/geNorm manual.pdf]

56. NormFinder - How to [http://mdl.dk/publication snormfinder.htm]. Link 'Documentation'.

Publish with Biomed Central and every scientist can read your work free of charge

"BioMed Central will be the most significant development for disseminating the results of biomedical research in our lifetime. "

Sir Paul Nurse, Cancer Research UK

Your research papers will be:

- available free of charge to the entire biomedical community

- peer reviewed and published immediately upon acceptance

- cited in PubMed and archived on PubMed Central

- yours - you keep the copyright 